Revista de Ciencias Sociales - Número 64 (2014) - Páginas 99-124

El club privado y su leve paso por la Corte Suprema

\title{
EL CLUB PRIVADO Y SU LEVE PASO POR LA CORTE SUPREMA
}

\author{
THE PRIVATE CLUB AND ITS SLIGHT \\ PASS FOR THE SUPREME COURTT
}

\author{
DANIELA BEATRIZ MARZI MUÑOZ* \\ Universidad de Valparaíso \\ dbmarzi@yahoo.it
}

\section{Resumen}

El artículo trata sobre la sentencia de la Corte Suprema a la acción de protección interpuesta por la presidenta del sindicato de trabajadoras de casa particular y de un diputado de la República en contra de un Club privado, cuyo reglamento impedía el acceso a dichas trabajadoras a ciertos espacios y exigía ciertos signos en su vestimenta para poder identificarlas y controlar la eficacia de su reglamento. En la sentencia considera que los denunciantes carecen de legitimidad activa y que no hay actos discriminatorios acreditados en el proceso. De ser la primera aserción correcta, se pone a la vista la consecuente falta de una acción adecuada para proteger el derecho a no ser discriminado por parte de estas trabajadoras. Más relevante todavía, devela una cuestionable concepción del derecho a no ser discriminado, provenientes del Tribunal que configuró recientemente las actuaciones calificadas de discriminatorias — en contra de una funcionaria del poder judicial— por parte de la Corte Interamericana de Derechos Humanos.

\footnotetext{
* Doctora por la Universidad Autónoma de Madrid. Artículo recibido el 23 de octubre de 2013 y aceptado el 21 de abril de 2014.
}

Revista de Ciencias Sociales - Número 64 (2014) - Universidad de Valparáíso - ISSN 0716-7725-Valparaíso, Chile 


\title{
Palabras claves
}

Autonomía privada, discriminación, garantías.

\begin{abstract}
The paper deals with the Supreme Court's decision on the protection action filed by the President of the Private Houses Worker's Union and a Representative of the Republic against a private Club, whose regulation forbade access to those workers into certain areas and demanded certain symbols on their clothes in order to identify them and to control the efficiency of their regulation. The decision considers that the complainants lack of active legitimacy and that there are no discriminatory acts proven within the process. If the first assertion is correct, it is evident the subsequent lack of an adequate action in order to protect the right not to be discriminated for these workers. Even more importantly, it reveals a controversial conception of the right not to be discriminated, coming from a Court which recently set the acts considered as discriminatory - against a Judiciary power employee - by the Inter American Court of Human Rights.
\end{abstract}

\section{Keywords}

Private Autonomy, discrimination, guarantees.

\section{Introducción}

No es un caso laboral, en realidad. Lo roza porque son trabajadoras de casa particular ${ }^{1}$ las afectadas y porque es un poder privado el que, prácticamente, no fue cuestionado por los Tribunales Superiores del país: tanto la Corte de Apelaciones de Santiago como la Corte Suprema rechazaron la acción de protección, salvo un voto de minoría del Supremo Sergio Muñoz.

Su principal argumento es la falta de legitimidad activa de los denunciantes: la presidenta del Sindicato de trabajadoras de casa particular y un diputado de la República. Pero no por eso los

1. Directamente usaré el término trabajadoras y no trabajadores, si bien es éste el que utiliza el Código del Trabajo en la normativa respectiva, Capítulo V, del Libro I, artículos 146 a 152 bis.

Facultad de Derecho y Ciencias Sociales - Universidad de Valparaíso - Chile 
sentenciadores pierden la oportunidad de decir que no encuentra en el proceso "la existencia cierta de un hecho concreto, acción u omisión, que prive, perturbe o amenace los derechos referidos, afectando su ejercicio por persona cierta y determinada”. Por lo que procedamos a revisar cuáles serían estos (no) hechos discriminatorios.

\section{Los hechos}

La presidenta del Sindicato de trabajadoras de casa particular y un diputado de la República recurren de protección, al tomar conocimiento, a través de los medios de comunicación ${ }^{2}$, de hechos discriminatorios que afectan a trabajadoras de casa particular cuyos empleadores son los socios de un Club privado. La discriminación estaría conformada por la exposición de las trabajadoras, a una norma —aquella contenida en el Reglamento del Club "Las brisas de Chicureo"- que ordena la delimitación de los espacios físicos en los que estas trabajadoras pueden circular, cuando ingresen con sus empleadores, quienes son los socios del Club.

Para alcanzar ese objetivo, el Reglamento da varios pasos ${ }^{3}$ : primero, señala que los menores de ocho años sólo pueden acceder a la piscina acompañados "de sus padres o hermanos mayores"; en seguida, "que en caso de utilizarse espacios exteriores como juegos, jardines o canchas de tenis, los niños podrán ser acompañados de una nana o niñera, la que deberá vestir uniforme o tenida que la identifique como tal"; pero que,

2. Se cita a la Revista Qué Pasa del 23 de diciembre de 2011, cuya nota da cuenta de una carta enviada a los socios del Club por parte de su directiva, la cual indicaba que "'Debido al aumento de niñeras en el sector piscina, les recordamos a nuestros socios el Artículo $\mathrm{N}^{\circ} 21$ '. Éste señala que niños menores de 8 años sólo podrán frecuentar el club acompañados de sus padres o hermanos mayores”. Disponible en: http://www.quepasa.cl/articulo/ojos-de-la-llave/2011/12/17-7269-9-polemicoinstructivo-sorprende-a-socios-de-brisas-de-chicureo.shtml

3. Según el establecimiento de hechos de la sentencia de la Corte de Apelaciones de Santiago RIC 25.031-2011, dictada por la Segunda Sala de Verano, presidida por la Ministra señora Adelita Ravanales Arriagada e integrada por la Ministra señora Jéssica González Troncoso y por el Abogado Integrante señor Antonio Barra Rojas.

Revista de Ciencias Sociales - Número 64 (2014) - Universidad de Valparaíso - ISSN 0716-7725-Valparaíso, Chile 
"en todo caso, dispone el instructivo que al sector de la piscina sólo podrán ingresar los socios, su grupo familiar y los invitados de éstos, negándose con ello el acceso de las nanas y niñeras".

De la lectura de las reglas que contiene el informativo, se puede deducir que el fin específico buscado es que las trabajadoras no accedan al sector de la piscina. Para darle eficacia a su mandato ordena que lleven una indumentaria que permita identificarlas "como tales", cosa que facilitaría el control del cumplimiento de lo prescrito.

Como la misma denuncia expresa, el recurrido no es el empleador de las afectadas. Ellas entran en la órbita de la autonomía privada del Club, expresada en su Reglamento, a causa de la relación de subordinación y dependencia que tienen con sus respectivos empleadores, quienes son los socios del Club. Así las cosas, cabe la pregunta, más allá de la calidad de trabajadoras de las personas afectadas y, no siendo, como dijimos, una causa netamente laboral:¿Qué hace que este fallo atraiga un comentario desde la disciplina? Que muestra cómo pasa con total superficialidad la posibilidad de hacerse cargo de argumentar por qué la autonomía privada puede tener como resultado reglas discriminatorias, el que a través de signos externos pretenda segregar de determinados espacios a personas por haber sido ubicadas en una determinada categoría ${ }^{5}$, cuyo elemento de configuración es un tipo de prestación laboral.

\section{El requisito procesal y la cuestión sobre la acción procedente}

En concreto, sostuvo la Corte Suprema, confirmando el criterio de la Corte de Apelaciones: "Que el recurso o acción de protección, no obstante su naturaleza tutelar, debe atenerse al mandato explícito del precepto 20 de la Carta Fundamental, cuyo claro tenor literal — primeroha personalizado su ejercicio, limitándolo sólo a quienes hubieren sufrido privación, perturbación o amenaza en sus derechos, a sus mandatarios, y a

4. Considerando segundo.

5. Este segundo argumento forma parte del voto de minoría del supremo Sergio Muñoz, el cual revisaremos más adelante con cierta detención.

Facultad de Derecho y Ciencias Sociales - Universidad de Valparaíso - Chile 
quienes comparezcan determinadamente en su favor. En seguida, ha objetivado su ámbito de aplicación, en cuanto exige, para su viabilidad, la existencia cierta de un hecho concreto, acción u omisión, que prive, perturbe o amenace los derechos referidos, afectando su ejercicio por persona cierta y determinada. Dicho en otra forma, y como se ha fallado, el arbitrio de protección no es una acción general o popular, que pueda interponerse por cualquier persona que no tenga interés inmediato y directo comprometido; ni tampoco es abstracta o potencial, puesto que requiere, sine qua non, a lo menos la concreción de una amenaza actual y real al legítimo ejercicio del derecho de alguien en particular. $5^{\circ}$ ) Que en la especie, ninguno de los recurrentes ha sufrido menoscabo en sus propios derechos, ni actúa en representación de ningún perjudicado en particular, ni ha logrado demostrar la amenaza o afectación del derecho de nadie en particular, no reuniéndose - en consecuencia - los presupuestos que el constituyente tuvo en vista para la procedencia del recurso" 6 .

Sobre la falta de legitimación activa de los denunciantes y la crítica a la acción de protección como sistema de tutela de los derechos fundamentales, son argumentos que exceden las posibilidades de este comentario. Pese a lo cual, trataré algunos aspectos significativos.

\subsection{La versión más individualista de los derechos}

Es importante señalar que la concepción de la titularidad de la acción de protección, patenta hasta la exasperación el corte más individualista de intelección de los derechos fundamentales, ya que encarna en términos absolutos la estructura de un derecho subjetivo que es ejercido por uno en contra de todos. Estructura que vehicula la crítica de que no es en la judicialización donde deben darse las respuestas a demandas sociales, (incluido el derecho al trabajo y demás derechos económicos, sociales y culturales). El razonamiento radica es que es en el ámbito de lo político en el que se presentan las preguntas por el interés de todos, lo cual pugna con la arquitectura de un derecho subjetivo, que es por esencia la pretensión de uno contra todos, o con prescindencia

6. Considerandos cuarto y quinto de la sentencia de la Corte de Apelaciones de Santiago.

Revista de Ciencias Sociales - Número 64 (2014) - Universidad de Valparáíso - ISSN 0716-7725-Valparaíso, Chile 
de las repercusiones que su ejercicio traiga al colectivo, sean éstas positivas o negativas, porque lo importante es que se tiene un derecho ${ }^{7}$.

Más allá de que esta perspectiva, ligada a una fundamentación histórica del surgimiento de los derechos fundamentales, rechaza una tendencia seria de las acciones vinculadas a derechos fundamentales: tanto internacional, como la del Sistema Interamericano de Protección de Derechos Humanos ${ }^{8}$, como los desarrollos nacionales, por ejemplo, aquél inherente al Derecho Colectivo del trabajo y que forma parte importante de su contribución específica, en orden a ampliar el acceso al proceso $^{9}$, incorporando el concepto de interés colectivo y, sin duda,

7. ATRIA, Fernando: "Existen los derechos sociales". En: Discusiones Doxa, $\mathrm{N}^{\circ}$ 4, 2004. Pág. 46, nota 105. Disponible en: http://bib.cervantesvirtual.com/ FichaObra.html? Ref=203013. Esta tesis conecta la expresión de los derechos "como cartas de triunfo, de Ronald Dworkin, defendida en Taking Rights Seriously, Duck worth, Londres, 1977. Pág. XI. Señala que sin hacer depender su planteamiento de "entidades fantasmas" como "voluntades colectivas", lo que implica que los individuos tienen derechos precisamente cuando las metas colectivas no son razones suficientes para negarles sus pretensiones: "Individual rights are political trumps held by individuals. Individuals have rights when, for some reason, a collective goals not a sufficient justification for denying them what they wish, as individuals, to have or to do, or not a sufficient justification for imposing some loss or injury upon them".

8. En rigor, el Sistema Interamericano configura una de las fórmulas más amplias consagradas en los instrumentos internacionales, OLÁSOLO, Héctor y GALAIN, Pablo: "La Influencia en la Corte Penal Internacional de la Jurisprudencia de la Corte Interamericana de Derechos Humanos en materia de acceso, participación y reparación de víctimas”. En: Sistema Interamericano de protección de los Derechos Humanos y Derecho Penal Internacional, Konrad-Adenauer e. V, 2010. Págs: 379 y 378. El artículo clave en esta materia es el 28. E, del reglamento de la Convención Americana sobre Derechos Humanos pues, según estos autores, permite sostener que el requisito esencial de acceso al Sistema Interamericano de protección de derechos humanos es la existencia de una víctima.

9. Basta recordar que el surgimiento del Derecho laboral, trajo consigo varias cosas nuevas: el reconocimiento de sujetos colectivos, (de la patronal y las representaciones obreras); la autonomía colectiva que rompe con los principios de la contratación civil y sus presupuestos; la creación de criterios objetivos de responsabilidad que socializan el riesgo de la actividad, etc. "Surge entonces el problema de la expresión de la voluntad de los sujetos colectivos, y en especial el

Facultad de Derecho y Ciencias Sociales - Universidad de Valparaíso - Chile 
lo que en su momento fue la disruptiva aparición del Sindicato en el proceso.

La apertura del proceso a la organización colectiva en su momento fue criticada. De esa resistencia registra el profesor Palomeque: "Uno sólo se piensa, el hilo conductor de una explicación plausible al rechazo institucional de la presencia del sindicato en el proceso de trabajo: la defensa de la cultura jurídica burguesa y de los valores e intereses que representa frente a la "colectivización que impone la mejor tutela de los propios intereses de clase de los trabajadores. El nivel jurisdiccional se ha querido así reservar de la 'contaminación' de las luchas sindicales, a cuyo fin concurren la construcción jurídica procesal y la formación profesional forense" ${ }^{10}$.

Sin embargo, para efectos de la sentencia en comentario, acá ni siquiera hablamos de derechos sociales, sino del inveterado derecho a no ser discriminado, cuya declaración de vulneración se pedía a la Corte $^{11}$.

mecanismo de representación del grupo y sus efectos. En este campo, las relaciones laborales que proceden de un contexto de relaciones entre sujetos privados, van adquiriendo un carácter público ostensible, tomando prestadas categorías que vienen del Derecho político", COURTIS, Christian y ABRAMOVICH, Víctor: "Los anillos de la serpiente. Transformaciones del Derecho entre el trabajo y el consumo”. En: Jueces para la Democracia, No 22, 1994. Pág. 55.

Disponible en: http://dialnet.unirioja.es/servlet/articulo? codigo $=2552529$

10. PALOMEQUE, Manuel Carlos: “Sindicato y proceso del trabajo". En:

Derecho del trabajo y razón crítica. Libro dedicado al profesor Manuel Carlos Palomeque en su vigésimo quinto aniversario como catedrático, Salamanca, 2004, Pág. 287. En el mismo sentido CRUZ VILLALÓN, Jesús, “Constitución y proceso del trabajo”. En: Valdés Dal Ré, Fernando y Cruz Villalón, Jesús, Lecturas sobre la reforma del proceso laboral, Ministerio de Justicia, Centro de Publicaciones, Madrid, 1991. Pág. 76.

11. Que es la dimensión de justiciabilidad que tiene siempre un derecho, en este aspecto es interesante revisar la contra argumentación a Courtis y Abramovich en su obra "Los derechos sociales como derechos exigibles", del profesor Atria: "Lo que un argumento inteligente da el derecho lo quita. Abramovich y Courtis entienden que los derechos sociales no pueden ser completamente exigibles, porque en una medida importante ellos dependen de sistemas que el juez no puede, por su tipo de

Revista de Ciencias Sociales - Número 64 (2014) - Universidad de Valparaíso - ISSN 0716-7725-Valparaíso, Chile 


\subsection{El derecho de acceso como elemento de la tutela judicial efectiva y fuente indirecta de legitimación democrática del poder judicial}

En términos mucho más generales, se ha planteado que "el derecho al acceso es, lógicamente, la más destacada manifestación del derecho a la tutela judicial efectiva" 12 , en que impera un principio pro actione, que vincula a los juzgados y tribunales: "al amparo de una abundante línea jurisprudencial constitucional podría afirmarse que el derecho al acceso al proceso lleva aparejada la correlativa obligación judicial de interpretar todos los requisitos y presupuestos legales condicionantes de acceso conforme al principio pro actione, es decir, la obligación de Jueces y Tribunales de no incurrir en interpretaciones de dichos obstáculos normativos que, valga la redundancia, obstaculicen o dificulten el que los litigantes puedan llegar a plantear ante ellos sus respectivas pretensiones y resistencias. Una interpretación judicial de las normas, en suma, que ha de llevarse a cabo del modo más favorable para el ejercicio de la acción, y no de tal manera que la obtención de una resolución de fondo (que debe entenderse como el modo normal de finalización de un proceso y de cumplimiento de la tutela judicial) sea dificultada u obstaculizada (v. STC 185/2006, de 19 de junio)"13.

Este tipo de lecturas "constitucionalizadas" del Derecho Procesal han permitido que el concepto de proceso evolucione también, de ser "un puro expediente formal ayuno de garantías en los sistemas políticos

cargo, crear (...) habiendo excluido esta dimensión de los derechos sociales, los autores creen poder rescatar algo todavía: la idea de que algunos aspectos de esos derechos son exigibles. Pero sorprendentemente (o, quizás: predeciblemente), cuando ellos proceden a determinar de modo preciso cuáles son estos aspectos, lo que aparece no son ni derechos sociales, ni las necesidades que los derechos sociales tienden a satisfacer: la principal dimensión de exigibilidad de los derechos sociales, la que 'queda siempre abierta', nos dicen los autores es la posibilidad de plantear judicialmente la violación de obligaciones del Estado por asegurar discriminatoriamente el derecho”, ATRIA, Fernando: “¿Existen los derechos sociales?”. En: Discusiones Doxa, № 4, 2004. Pág. 44.

12. GARBERÍ, José: Constitución y Derecho Procesal, Cuadernos Civitas, Thompson Reuters, Madrid, 2009. Pág. 159.

13. GARBERÍ, José, ob. cit. Pág: 142.

Facultad de Derecho y Ciencias Sociales - Universidad de Valparaíso - Chile 
totalitarios se ha tornado, en las modernas democracias constitucionales, en un conjunto de actuaciones procedimentales sofisticado, complejo y plagado de garantías"14.

Y lo anterior, se vincula a una finalidad incluso mayor: una vía de legitimación democrática del Poder del Estado más cuestionado por considerarse un poder contramayoritario. Constatado que la legitimidad democrática no puede provenir de la fuente que posibilita su acceso, ésta podrá emanar de "las exigencias que la sociedad demanda de sus jueces, en la calidad de la respuesta que la ciudadanía espera de ellos cuando les somete el enjuiciamiento de un determinado conflicto (...) orientación que podría sintetizarse afirmando que los jueces se encontrarán democráticamente legitimados, aun de manera muy indirecta, cuando desempeñen la potestad jurisdiccional de manera independiente (o no interesada o contaminada), pronta o eficaz (pues, como suele decirse con todo fundamento, una justicia tardía no es justicia; y, sobre todo, con escrupuloso apego a la legalidad vigente"15. Para el profesor Ferrajoli, quien es un constante defensor del positivismo y no puede ser acusado de defensor del "activismo judicial" ni nada que se le parezca, es esa independencia del juez ${ }^{16}$, unida al hecho de su transformación de garante de los derechos fundamentales, la que explica la relevancia de su figura actual en el panorama jurídico y la que ha brindado renovada legitimidad democrática. Es esa independencia la que le permite cumplir con la lectura constitucional del Derecho y en caso de contradicción, denunciarla. Y ello porque dicha tarea no tiene que ver con asuntos entregados a las mayorías. "Esta legitimación no tiene nada que ver con la democracia política, ligada a la representación. No deriva de la voluntad de la mayoría. Su fundamento es únicamente

\footnotetext{
14. GARBERÍ, José, ob. cit. Pág: 34.

15. GARBERÍ, José, ob. cit. Pag. 50.

16. Para el Sistema Interamericano, uno de los objetivos principales del principio de separación de poderes en la actualidad, es preservar la independencia de los jueces, Caso Tribunal Constitucional versus Perú, Fondo, Reparaciones y costas, párrafo 73, sentencia de 21 de enero de 2001. Disponible en: http://www.corteidh.or.cr/ docs/casos/articulos/Seriec_55_esp.pdf
}

Revista de Ciencias Sociales - Número 64 (2014) - Universidad de Valparáíso - ISSN 0716-7725-Valparaíso, Chile 
la intangibilidad de los derechos fundamentales. Y sin embargo es una legitimación democrática de los jueces, derivada de su función de garantía de los derechos fundamentales, sobre la que se basa la que he llamado "democracia sustancial" 17.

El artículo 20 de la Constitución establece que cualquiera a nombre de la víctima puede actuar, lo que de cierta forma es una norma amable en cuanto a la desformalización de la representación. El problema es que la Corte para desestimar la acción consideró como elemento insalvable, el que no se había apersonado una víctima concreta que se haya visto lesionada por el efecto del reglamento. Es ahí donde radica el primer error, desde mi punto de vista, del voto de mayoría, porque una lectura pro actione debió haber estimado, al menos en la representante sindical, una persona habilitada para ejercer el derecho a impugnar el reglamento, cuyos efectos irradian en forma permanente a un grupo indeterminado de personas de quien ella es representante en ejercicio de un derecho fundamental, como es la libertad sindical ${ }^{18}$. Representante de las trabajadoras de los socios, que se encuentran en una posición de vulnerabilidad respecto del poder que las agrede.

\subsection{La pregunta por la acción procedente (y plausible)}

Da ocasión una sentencia como esta, de rememorar las arduas críticas que desde la vereda laboral se realizara a la acción de protección como vía procesal de ejercicio de los derechos fundamentales de los

17. FERRAJOLI, Luigi: "El Derecho como sistema de garantía”. En: Revista Jueces para la democracia, No 16-17, 1992. Pág. 66.

Disponible en: http://dialnet.unirioja.es/servlet/articulo? codigo $=2551827$

18. Lo cual dependería a su vez, de la lectura que realicen de dicho derecho, que como siempre no es unívoca y puede ir de una apegada al Derecho Internacional (y que también desborda las posibilidades del comentario), o a la norma ordinaria chilena, que proviene intocada en sus nudos centrales, de dos decretos de la Dictadura, $\mathrm{N}^{\text {os }} 2.756$ y 2.758 , ambos de 1979, conocidos por el nombre "Plan Laboral", sobre esta materia ver CAAMAÑO, Eduardo y UGARTE, José Luis: Negociación colectiva y libertad sindical: un enfoque crítico, Legalpublishing, Santiago de Chile, 2009.

Facultad de Derecho y Ciencias Sociales - Universidad de Valparaíso - Chile 
trabajadores ${ }^{19}$ y permitía darle una bienvenida entusiasta a la tutela de derechos fundamentales que aparejaba la vigencia de la Reforma Procesal Laboral ${ }^{20}$.

En ese sentido, la tutela de derechos fundamentales contempla una legitimación activa amplia. El artículo 486 del Código del Trabajo, contempla varios supuestos de ejercicio de la acción:

Cualquier trabajador u organización sindical, invocando un derecho fundamental o interés legítimo, en el ámbito de las relaciones jurídicas cuyo conocimiento corresponde a la jurisdicción laboral. Excepción a que pueda denunciar cualquier trabajador u organización sindical es que la lesión se produzca con ocasión del despido, caso en el cual la titularidad se restringe sólo al trabajador afectado.

Si se trata de la organización a la que el trabajador afectado pertenece ésta puede intervenir como tercero coadyuvante o como denunciante principal, lo cual dependerá de lo que procesalmente le parezca mejor ${ }^{21}$, ya que el sentido de esta norma procesal laboral es legitimar activamente al sindicato ${ }^{22}$.

19. Ver UGARTE, José Luis: "Los derechos fundamentales y la relación laboral: el largo camino a los tribunales". En: Anuario de la Sociedad Chilena de Derecho del Trabajo, $\mathrm{N}^{\circ}$ 2, Santiago de Chile, 2001; en relación a la capacidad enervante de la acción de protección a la función fiscalizadora y tutelar de la Inspección del Trabajo, GAMONAL, Sergio, "La fiscalización de la Dirección del Trabajo frente al recurso de protección”, Boletín Oficial Dirección del Trabajo, N ${ }^{\circ}$ 236, septiembre de 2008 y actualizado en Trabajo y Derecho, Legalpublishing (segunda edición), Santiago de Chile, 2012. Págs. 75 y siguientes.

20. Articulada en las Leyes $\mathrm{N}^{0}$ 20.022, que crea los Tribunales de Cobranza Laboral y Previsional; 20.023, sobre normas para la cobranza judicial de cotizaciones, aportes y multas de las Instituciones de Seguridad Social, ambas de 2005; y 20.087, que modifica el procedimiento de juicio del trabajo, del año 2006.

21. En términos prácticos ninguna diferencia en cuanto a derechos para intervenir en el proceso representa el actuar como parte principal o tercero coadyuvante, salvo que éste se incorpora luego de la denuncia y, que deberá cumplir con dos prevenciones contenidas en el Código de procedimiento civil (C.P.C.): no retrotraer el juicio a momentos anteriores, (que adquirirá importancia según cuándo se incorpore al proceso); y no entorpecer la marcha del juicio, artículos 23 en relación al artículo 17 del C.P.C.

22. Por lo mismo, no se detiene en establecer que el trabajador podría ser tercero coadyuvante de la denuncia de la organización sindical, pues para ello bastan las reglas generales del C.P.C. Sobre este punto agradezco las observaciones del profesor 
La Inspección del trabajo si actuando en el ámbito de sus atribuciones toma conocimiento de una lesión de derechos fundamentales, tiene el deber de denunciar.

Sin embargo, el punto central queda igualmente en suspenso pues el denunciado no es el empleador. Y salvo que se plantease una demanda de tutela en contra de estos empleadores, por su responsabilidad en llevar a sus trabajadoras, en razón de su potestad directiva, y exponerlas a esta autonomía privada ejercida en términos inconstitucionales, aun así, todo esto es un escenario improbable si es que no delirante: ¿qué se ganaría?, ¿̇una indemnización obtenida de un empleador (que mantiene su poder de desahuciar el contrato), una orden de no llevarlas a esos espacios?

Esa es la trascendencia de admitir la defensa de la organización sindical en defensa de un interés legítimo. Al producirse una discriminación que vincula a trabajadores, quienes por estructura están sometidos a un poder privado, se produce la necesidad de habilitar a sus representaciones quienes defienden no derechos subjetivos sino intereses legítimos, todos lo cual actúa reequilibrando dicho desequilibrio de poder y haciendo plausible el ejercicio y restauración de derechos, sin que se llegue a la más común de las situaciones cual es que el accionar ante tribunales acontezca una vez producido el despido. Es por esto mismo, que tampoco la ley 20.609 de 2012, llamada "Ley antidiscriminación”, salva este problema propio del trabajo, pues la legitimación activa sólo contempla la actuación de alguien distinto a la víctima concreta, cuando ésta se encuentre "imposibilitada de ejercerla", (artículo 3, inciso segundo). Sin embargo, lo que sí existe en la acción de tutela de derechos fundamentales laboral es la habilitación para deducir la acción no en nombre de otro, sino al propio nombre y en

Felipe Gorigoitía Abbott. La reforma a la jurisdicción social operada por la LRJS 36/ 2011 , trajo mayor amplitud a la legitimación activa, permitiendo, en aquellos casos en los que dicha legitimación pertenezca al trabajador, actuar como terceros coadyuvantes, no sólo a la organización sindical, como lo permitía el artículo 175.2 de la LPL, sino también a las entidades públicas o privadas entre cuyos fines se encuentre la promoción y defensa de los intereses legítimos afectados, aunque manteniendo la limitación de que no podrán personarse, recurrir ni continuar el proceso contra la voluntad del trabajador perjudicado, artículo 177.2.

Facultad de Derecho y Ciencias Sociales - Universidad de Valparaíso - Chile 
protección de un interés que le pertenece, denominado "legítimo" - y no un derecho subjetivo-. La noción que nace en el ámbito de la jurisprudencia administrativa francesa para ser luego recogida luego en el ámbito laboral, cuya definición de interés es "el que tienen aquellas personas que, por razón de su situación objetiva en que se encuentren, por una circunstancia personal o por ser destinatarios de una regulación sectorial, son titulares de un interés propio, diferente del de cualquier ciudadano, a que los poderes públicos actúen de acuerdo con el ordenamiento cuando, con motivo de persecución de fines de interés general, inciden en el ámbito del interés propio. Entendida como situación jurídica individualizada desde la perspectiva procesal, comporta una específica relación con el objeto de la pretensión y, desde la sustantiva, alude al contenido de la esfera personal, excluyente de la actuación en favor de los terceros, la noción de interés legítimo nace y se desarrolla en el ámbito del interés público, del que trae su razón de ser" ${ }^{23}$. Sin embargo, la relación entre el derecho subjetivo y el interés legítimo no es tanto de conceptos distintos, sino que se tiene un interés sobre "un derecho subjetivo verdadero, aun siendo de otra especie que los derechos activos o típicos, derecho que puede exigir medidas de restablecimiento específicas, distintas de la simple eliminación del acto o disposición invasoras del propio círculo vital”24, permitiendo así una mayor fiscalización de las actuaciones.

Rojas Rivero, compartiendo la explicación de que interés legítimo es básicamente la "situación jurídica específica en la que se encuentra un sujeto respecto a una norma objetiva, de manera que el cumplimiento de la misma le produce un beneficio, mientras que su infracción le ocasiona un perjuicio en su esfera vital", destaca que es una facultad reaccional o impugnatoria, cuyo objetivo es el mantenimiento o restablecimiento íntegro de una situación jurídica. Por ello, si bien la

23. VALDÉS DAL -RÉ, Fernando: "El proceso de protección de la libertad sindical y demás derechos fundamentales”. VALDÉS DAL - RÉ, Fernando y CRUZ

VILLALÓN, Jesús: Lecturas sobre la reforma del proceso laboral, ob. cit. Pág. 493.

24. En cita a García de Enterría, VALDÉS DAL-RÉ, Fernando: "El proceso de protección de la libertad sindical y demás derechos fundamentales”, VALDÉS DAL- RÉ, Fernando y CRUZ VILLALÓN, Jesús: Lecturas sobre..., ob. cit. Pág. 494. 
distingue de una acción popular porque no es una facultad cuyo objetivo sea el puro respeto de la legalidad, no la desengancha de su origen administrativo, a partir del cual siempre representó un punto de inflexión entre garantizar la legitimidad del ejercicio del poder e instrumentalmente conseguir la eventual realización del interés sustancial del privado ${ }^{25}$. En ese confín, se explica la habilitación amplia, por la relación que se tenga con una norma, entendida esta relación de forma más general, como en el caso del interés legítimo, para solicitar una intervención judicial de dimensiones extensas. Así, se aprecia que desde el nacimiento de la noción de interés legítimo, éste constituyó un impulso a revisar los deslindes de lo público y lo privado ${ }^{26}$. Tales tendencias son percibidas como "crisis del Derecho", que bien puede ser percibida en un sentido positivo, en tanto normal revisión de los criterios de distinción para redefinir la dinámica de los dos términos ${ }^{27}$. Este tipo de movimientos, sin embargo, no pueden ser percibidos como crisis o puntos de inflexión dentro del Derecho del Trabajo, pues a su base siempre ha estado la existencia de intereses legítimos, sobre la conexión entre intereses individuales y colectivos que redefinieron los límites de los poderes empresariales ${ }^{28}$.

Nuestra norma en este punto difiere de lo que permitiría el procedimiento de tutela de derechos fundamentales español, que autoriza a utilizar esta vía contra terceros vinculados al empleador "a cualquier título", en la medida que "la vulneración alegada tenga

25. ROJAS RIVERO, Gloria: El derecho del trabajador al ejercicio individual de las acciones derivadas del contrato de trabajo, Civitas, Madrid, 1994. Pág. 64.

26. "El interés legítimo, siendo una categoría más amplia que la de derecho subjetivo - cuya insuficiencia como tal categoría se pone de relieve hoy por la doctrina-, no puede confundirse con la acción popular, entendida lisa y llanamente como el interés por la legalidad", para Rojas Rivero es preferible establecer esa frontera caso a caso y no a priori por medio de una definición conceptual, ob. cit. Pág. 62.

27. ROJAS RIVERO, Gloria, El derecho del trabajador al ejercicio individual de las acciones derivadas del contrato de trabajo, ob. cit. pp. 62-63.

28. ROJAS RIVERO, Gloria, El derecho del trabajador al ejercicio individual de las acciones derivadas del contrato de trabajo, ob. cit. Pág. 67.

Facultad de Derecho y Ciencias Sociales - Universidad de Valparaíso - Chile 
conexión directa con la prestación de servicios”29. Esta norma recoge la solución jurídica de la STC 250/2007, de 17 de diciembre, que consideró que rechazar la demanda en contra de otro trabajador, dependiente de otra empresa, acusado de acoso sexual, era equivocado ya que implicaba una interpretación restrictiva del artículo 2 , a) de la anterior ley procesal —Ley de Procedimiento Laboral — en circunstancias de que lo relevante no es quien sea el agresor, sino que la vulneración se produzca dentro del ámbito de trabajo.

Cabe anotar que el transformar al empleador en centro de imputación final de responsabilidad, es una tendencia en materia laboral, en contraposición a su poder de configurar la organización y las relaciones laborales de las que es titular: "Con todo, la potestad de mando del empleador configura una responsabilidad por la salud del trabajador lo que lo indica como el centro de imputación de responsabilidad por los atentados a la dignidad de sus trabajadores"30.

Ante la pregunta ¿para qué demandar al empleador?, si hasta aquí, el Club privado, permanecería incólume y su reglamento intocado, y, enfrentados a la respuesta "para nada", volvamos a la acción de protección.

No debe olvidarse que esta sentencia tuvo un voto de minoría que estuvo por acoger la denuncia, mirando directa, aunque someramente, qué es lo que tenía ante sus ojos para conocer: un

29. Artículo 177, $\mathrm{N}^{\circ}$ 1, parte final de la Ley Reguladora de la Jurisdicción Social: "Cualquier trabajador o sindicato que, invocando un derecho o interés legítimo, considere lesionados los derechos de libertad sindical, huelga u otros derechos fundamentales y libertades públicas, incluida la prohibición de tratamiento discriminatorio y del acoso, podrá recabar su tutela a través de este procedimiento cuando la pretensión se suscite en el ámbito de las relaciones jurídicas atribuidas al conocimiento del orden jurisdiccional social o en conexión directa con las mismas, incluidas las que se formulen contra terceros vinculados al empresario por cualquier título, cuando la vulneración alegada tenga conexión directa con la prestación de servicios".

30. GAMONAL, Sergio y UGARTE, José Luis: "Acoso sexual y moral en el lugar de trabajo”. En: XX Congreso Mundial de la Sociedad Chilena de Derecho del Trabajo y de la Seguridad Social, Santiago de Chile, 25-28 de septiembre de 2012. Pág. 16.

Revista de Ciencias Sociales - Número 64 (2014) - Universidad de Valparaíso - ISSN 0716-7725-Valparaíso, Chile 
producto de la autonomía privada, en que por lo demás, no se pretendía dar una norma para "autogobernarse", sino para regular conductas de terceros que, sólo a causa de un vínculo de subordinación con los socios, se veían obligados a entrar en la esfera de poder del Club.

\section{El inexplorado surco de la autonomía privada}

La autonomía privada, se vincula a un ámbito protegido de intervención de terceros, y responde a valores y derechos tan determinantes como el pluralismo y el desarrollo libre de la personalidad. En otras palabras, de una muy reputada doctrina civilista, encuentra su tutela jurídica, nada menos que "en la idea misma de persona. Si la persona es un ser de fines cuya dignidad, derivada de su naturaleza racional, el ordenamiento jurídico no puede dejar de reconocer, no cabe ninguna duda que debe reconocerse a la persona un ámbito de autosoberanía para reglamentar sus propias situaciones jurídicas y a través de ellas dar cauce a sus fines, intereses y aspiraciones (...) A esta idea de poder de autogobierno de los propios fines, nosotros la hemos denominado 'autonomía privada'. El contrato tiene pues su fundamento más hondo en el principio de autonomía privada" 31 .

Tiene protección constitucional, en aquella brindada a los grupos intermedios $^{32}$ y en el derecho de asociación ${ }^{33}$. Se relaciona, evidentemente, con la democracia.

Diversas construcciones se elaboran a su respecto, dependiendo si la asociación corresponde a una figura de rango constitucional, como el Partido Político o el Sindicato ${ }^{34}$, en que sus Estatutos están indiscutiblemente sometidos al principio democrático y pueden ser cuestionados por vulnerar derechos fundamentales ${ }^{35} \mathrm{y}$, asimismo, en

31. DIEZ- PICAZO, Luis: Fundamentos del Derecho Civil Patrimonial, Editorial Tecnos, (segunda edición), Madrid, 1979. Pág. 92.

32. Artículo 1 inciso tercero, de la Constitución chilena.

33. Artículo 19, $\mathrm{N}^{\circ} 15$ de la Constitución chilena.

34. Artículo 19, $\mathrm{N}^{\circ} 15$ inciso cuarto y $\mathrm{N}^{\circ} 19$ de la Constitución chilena.

35. Pero que a su vez, tienen un tratamiento especial en cuanto a las relaciones laborales que establecen, en específico a las "tareas de tendencia”, que incluye

Facultad de Derecho y Ciencias Sociales - Universidad de Valparaíso - Chile 
cualquier clase de asociaciones, todas las cuales admiten diversos matices si es que hablamos de las relaciones que entablan en un plano, al menos supuesto, de igualdad (por ejemplo, socios entre sí), o de subordinación (empleador/trabajadores $)^{36}$, y en todas ellas se despliega el trascendental debate de la primacía entre lo colectivo sobre el individuo, o vice- versa ${ }^{37}$.

además de Sindicatos, Partidos Políticos, a las confesiones religiosas, en que por ejemplo pueden implicar una restricción más acentuada a la general que se impone por una relación laboral, en atención a que en ellas la ideología es un elemento esencial y que les da la operatividad, (aunque partiendo de la premisa que en toda empresa subyace un elemento ideológico), pero no toda relación laboral de una empresa de tendencia amerita este tratamiento especial. Sobre el punto, en extenso ROJAS, Gloria: "La libertad de expresión del trabajador”, Trotta, Madrid, 1991. Págs. 191-207-209.

36. Sobre los poderes empresariales y las dudosas raíces constitucionales de la potestad disciplinaria, una interesante lectura es la de los profesores Gamonal y Guidi, quienes que identifican su justificación en su origen como requerimiento práctico, perteneciente a un determinado momento histórico: el siglo XVIII y emergente necesidad de proteger esta nueva forma de riqueza conformada por bienes que se almacenan, los que, por tanto, están expuestos a depredación. Y no a un verdadero soporte jurídico basado en la propiedad o en la libre iniciativa económica, pues, como retrata el provocativo ejemplo que consigna: "El derecho de propiedad en sí no faculta para una potestad particular sancionatoria tan intensa como la descrita. Si invito a alguien a mi casa o llevo en mi auto a una persona, el ser dueño de la casa o del auto no me faculta para sancionarlo disciplinariamente", GAMONAL, Sergio y GUIDI, Caterina: Manual del contrato de trabajo, Legalpublishing, (primera edición), Santiago de Chile, 2010. Pág. 99. Lo que muestra un debate apenas iniciado en torno a los límites de los poderes empresariales. Para Mattia Persiani una diferencia del Derecho antes del surgimiento del Derecho del Trabajo y después de ese evento, es precisamente entender que los poderes empresariales no se vinculan al derecho de propiedad, PERSIANI, Mattia: "Il potere direttivo e l'organizzazione del lavoro". PERSIANI, Mattia y CARINCI, Franco, Trattato di Diritto del Lavoro, Cedam, Padova, 2012. Págs: 402-413-414-783.

37. En Alemania, por ejemplo, la composición de los intereses de la asociación y los del socio ha de realizarse, se dice, con respeto al contenido valorativo del derecho fundamental de asociación, pero sin que ninguna de las dos partes pueda ejercer una pretensión frente a la otra con fundamento inmediato en el derecho fundamental de asociación, en cuanto éste proyecta su mandato de protección por igual sobre los dos: la asociación y la parte ${ }^{37}$. Una opción distinta ha sido la de la jurisprudencia civil española, que ha estimado que ambas partes pueden "fundar sus

Revista de Ciencias Sociales - Número 64 (2014) - Universidad de Valparáíso - ISSN 0716-7725-Valparaíso, Chile 
En este punto, las ideas matrices suelen ser faros opuestos para lo que se concibió como dos mundos distintos: "el ámbito de lo público se rige por la democracia y el de lo privado, por la libertad"38.

Esta forma de categorizar la realidad a su vez se ha relativizado, en especial gracias a la acción del feminismo, que ha levantado temas que parecían profundamente privados, como la violencia doméstica, hasta transformarlos en debate y políticas públicas, lo que demuestra que no hay un esencialismo para situar un tema en una u otra categoría ${ }^{39}$. Como se dijera "las libertades públicas no experimentan ninguna variación de naturaleza por el hecho de que se desarrollen entre particulares o con relación a un poder público. No existen libertades privadas por la desaparición del poder público, obrando como tal, en la relación entablada. Todas las libertades son públicas en el sentido que tienen su regulación en textos públicos y gozan también de la protección del Estado. La misma libertad no varía de naturaleza por el hecho de realizarse frente a un sujeto público o privado" ${ }^{40}$.

pretensiones u oponerse a ellas haciendo valer poderes de autoorganización o de participación derivados de dicho derecho fundamental", VON MÜNCH, Ingo: "Drittwirkung de derechos fundamentales en Alemania". En: Cardoch, Pablo, Asociaciones, derechos fundamentales y autonomía privada, Civitas, Madrid, España, 1997. Pág. 140.

38. VON MÜNCH, Ingo, ob. cit. Pag. 15.

39. "Hasta hace poco, por ejemplo, las feministas eran minoría en pensar que la violencia doméstica contra la mujer era un asunto de interés común y, por consiguiente, un tópico legítimo de discurso público, la gran mayoría de la gente consideraba que era un asunto privado que concernía únicamente a un número reducido de parejas heterosexuales (...) Las feministas formábamos entonces un contrapúblico subalterno desde el cual propagábamos la idea de que la violencia doméstica es un rasgo sistémico y muy difundido en las sociedades patriarcales. Eventualmente, después de una oposición discursiva sostenida, conseguimos convertir este asunto en un problema de interés común. El punto es que, a este respecto, no existen fronteras naturales dadas a priori”. FRASER, Nancy: Iustitia Interrupta. Reflexiones críticas desde la posición "postsocialista”, Siglo del Hombre, Universidad de Los Andes, Bogotá, 1997. Pág. 123.

40. EMBID, Antonio: "El Tribunal Constitucional y la protección de las libertades públicas en el ámbito privado”, REDA, N²5, 1980. Pág. 7.

Facultad de Derecho y Ciencias Sociales - Universidad de Valparaíso - Chile 
De ahí, se desgaja un debate sobre las circunstancias que harían admisible la intervención del juez ${ }^{41}$.

Afortunadamente, lejos estamos, al menos en términos teóricos, de considerar que la autonomía es la esfera en que nos encontramos exentos de rendir cuentas públicas ${ }^{42}$, o al menos, no puede ser entendido como un ámbito ajeno a la responsabilidad, porque implicaría que hay espacios de ejercicio de poder que escapan al Derecho, y como es sabido donde hay asociación hay poder: "Ya que el poder humano corresponde a la condición de pluralidad, para empezar"

41. Por ejemplo, un planteamiento es que "En este orden de ideas, los autores quieren llamar la atención sobre tres abusos obvios: El primero el incumplimiento de los estatutos o, lo que es lo mismo, la convalidación de interpretaciones arbitrarias de su texto: quienes ingresan en una asociación, quienes lo pretenden y quienes desean permanecer en ella tienen derecho a que las reglas del juego en el que aceptan o aceptaron participar se cumplan hasta el final. Y si estas reglas ceñían de algún modo el ámbito y contenido de las decisiones de los órganos rectores de la asociación, los interesados podrán acudir a los tribunales en petición de tutela judicial. El segundo es el monopolio: una asociación que detenta una posición de monopolio no puede regirse por cualquier tipo de estatutos, pues la falta de competencia en el sector en el que desarrolla sus actividades convertirían en irrisoria la libertad de asociación que está en la base del derecho público y privado de las asociaciones (...). El tercero está integrado por el resto de los derechos fundamentales y, paradigmáticamente, por el derecho a la igualdad del artículo $14 \mathrm{CE}$ : en este fin de siglo, el triunfo de la democracia socioliberal frente a las ideologías totalitarias que ensombrecieron muchos - la mayoría — de los años que lo componen no es sinónimo, de nuevo, de la apoteosis del mercado como mecanismo universal de regulación de las relaciones sociales, pues en un estado social y democrático de derecho no todo se puede comprar y vender, y el derecho fundamental a la libertad de asociarse como plazca a los interesados está limitado por el resto de normas constitucionales sobre derechos fundamentales”, VON MÜNCH, Ingo, ob. cit. Págs. 18-19.

42. Por ejemplo, J.D. Moon considera los “derechos subjetivos protegen una esfera dentro de la cual las personas privadas quedan desatadas de la obligación de tener que responder públicamente de sus acciones y omisiones”, citado por HABERMAS, Jurgen: Facticidad y validez, Editorial Trotta, (sexta edición), Madrid, 2010. Pág. 391.

43. ARENDT, Hannah: La condición humana, Paidós, (primera Edición en español), Barcelona, 2005. Pág. 227. En términos virtuosos, por algo el de asociación es el primero de los derechos, pues es el “derecho a tener derechos", en la

Revista de Ciencias Sociales - Número 64 (2014) - Universidad de Valparáíso - ISSN 0716-7725-Valparaíso, Chile 
Algo tan salvaje no ha sido sostenido expresamente por la Corte Suprema, sólo ha permitido que suceda ante sus ojos. La pregunta se traslada entonces a, enfrentados a esta autonomía privada, cuál es el fin que se ha planteado y qué valoración debiera darle el Derecho, qué forma de ser valiosa expresa esta regulación del Club, como para que sea tutelada por el Derecho Y en esto el Ministro Muñoz fue incisivo: su fin es discriminar a un grupo por medio de signos externos que lo identifiquen como tal, provocando su segregación física. Elegante forma de decir que las empleadas no entren al sector de la piscina. El voto disidente del Ministro Muñoz, señaló: "El hecho de impedir a una persona poder entrar a un lugar o espacio por motivos de raza, sexo, idioma, religión o cualquiera otra circunstancia étnica, social o cultural implica un trato discriminatorio que contraviene principios básicos de los derechos humanos plenamente asentados en la sociedad moderna y que se encuentran contenidos en la Carta de las Naciones Unidas, Pacto Internacional de Derechos Civiles y Políticos, Convención Americana sobre Derechos Humanos que son leyes de la República". Continúa la opinión disidente: "Esta Corte Suprema de Justicia, en su función cautelar de los derechos fundamentales, le corresponde orientar la convivencia nacional en un plano de absoluta igualdad entre las personas, sin que sea posible amparar conductas que atenten en contra de esta garantía. Obligar que una persona utilice una determinada vestimenta que la identifique con un trabajo o función que, en el medio que se emplea, tiene un desvalor o una connotación de segregación, constituye una conducta discriminatoria que en nada se diferencia de la identificación por razones étnicas, políticas, sociales o religiosas que ha conocido la historia. Chile es una república y en ella todos sus habitantes gozan de igualdad de trato y derechos, sin que existan clases privilegiadas,

terminología de la misma Arendt, y en ese entendido vinculable a la libertad sindical, en esa interpretación ver UGARTE, José Luis, "El trabajador en su soledad -El modelo de relaciones laborales chileno y la promesa no cumplida-”, 2010, (inédito). Pág. 24. Pero también con una deriva más riesgosa: toda asociación tiene que lidiar con el dilema del poder hacia su interior. Del equilibrio entre "el todo y la parte", que reproduce también el peligro del transpersonalismo. Muy certeramente se ha criticado que la "organización es la madre del dominio de los elegidos sobre los electores, de los mandatarios sobre los mandantes, de los delegados sobre los delegantes”, en cita a Robert Michels, VON MÜNCH, Ingo, ob. cit. Pág. 75.

Facultad de Derecho y Ciencias Sociales - Universidad de Valparaíso - Chile 
como tampoco personas que puedan ser discriminadas arbitrariamente. Es por ello que el recurso debe ser acogido, prohibiendo la conducta reprochada, la cual no logra ser superada con una modificación estatutaria que refleja mayor segregación por razones sociales".

Valga aclarar que el que la autonomía privada tenga límites no es una lectura de avanzada. Reputada y tradicional doctrina civilista ha explicado que la autonomía privada siempre ha encontrado límites en las voces ley, moral y orden público” ${ }^{4}$.

\section{Palabras finales: una Corte Suprema en pleno oleaje del fallo Atala}

Esta sensibilidad, por llamarlo de alguna manera, por parte del tribunal de más alta jerarquía de nuestro país, ante la discriminación de un grupo que además está constituido por mujeres, y que incluso se encuentra más precarizado que la generalidad de los trabajadores — de acuerdo a la propia norma, el Derecho del Trabajo, cuyo fin es, paradójicamente su protección- debe llevarnos al menos a reflexionar. La Corte no pudo o no quiso ir contra un reglamento de un Club, que para efectos de la causa no es más que un hecho. No se trataba de la anulación de una ley, que se vería entonces beneficiada por el principio de deferencia al legislador, dada su "posición institucional en la democracia" 45 . Simplemente se trata de un grupo que sostiene valores que, manifestados por medio de su autonomía privada, producen

44. DIEZ- PICAZO, Luis, ob. cit. Pag: 163. Así desde el Código francés de 1804, que fijaba los límites de la autonomía privada en "la ley, el orden público y las buenas costumbres”, Gamonal Contreras, Trabajo y Derecho, ob. cit. Pág. 59. Incluso la doctrina de la eficacia mediata de los derechos fundamentales se afirma que ella se ejercería "a través de las cláusula generales del Derecho civil como el orden público o las buenas costumbres o los conceptos jurídicos indeterminados. El Tribunal Constitucional ha seguido esta orientación mayoritariamente desde la conocida sentencia Luth”, EMBID IRUJO, Antonio, ob. cit. Pág. 8, en cita a Durig.

45. UGARTE, José Luis: "La colisión de derechos fundamentales en el contrato de trabajo y el principio de proporcionalidad, Tesis para optar al grado de doctor por la Universidad de Salamanca, 2012.

Disponible en: http://www.tesisenred.net/handle/10803/649/browse? $v a l u e=$ Ugarte + Cataldo\%2C + Jos\%C3\%A9+L.\&type $=$ author

Revista de Ciencias Sociales - Número 64 (2014) - Universidad de Valparáíso - ISSN 0716-7725-Valparaíso, Chile 
resultados inconstitucionales. Es difícil sostener que se merma el libre desarrollo de la personalidad y perjudica el pluralismo al negar que los particulares puedan regular sus relaciones entre sí, en términos de producir efectos discriminatorios.

A estas alturas resulta indiscutible que los particulares no pueden darse un trato discriminatorio, menos cuando se trata de causas de aquellas que la legislación estableció como criterios sospechosos ${ }^{46}$ y que corresponden a patrones que la política antidiscriminatoria tuvo como primer objetivo erradicar de la sociedad: "En este mismo ámbito, la prohibición de discriminación contenida en el segundo inciso del art. 14 fue concebida inicialmente como una manifestación más del genérico principio de igualdad. La referencia expresa a determinadas circunstancias motivadoras de una diferencia de trato no tendría, según estas primeras interpretaciones, otra virtualidad que la de manifestar una especial preocupación del constituyente dirigida a erradicar determinados elementos diferenciadores tradicional e históricamente arraigados en la sociedad. Sin embargo, la práctica ha ido progresivamente poniendo de manifiesto cómo la prohibición tajante de tales discriminaciones, a pesar de su inicial calificación como una concreción del principio de igualdad, tiene consecuencias prácticas propias y diferentes de las que aquel derecho. En efecto, si la existencia de un trato desigual en la norma exige una justificación objetiva y razonable, justificación que se efectúa normalmente alegando cualquier causa que elimine la sospecha de arbitrariedad, la fundamentación de la desigualdad en una circunstancia discriminatoria tiene en el ejercicio del poder disciplinario el efecto práctico de "endurecer hasta sus máximas consecuencias" ${ }^{47}$. En este caso, el juez estaría llamado a descubrir qué razonamiento existe para segregar a las trabajadoras de casa particular, e hilar que son mujeres que concretamente pertenecen a una categoría dentro del mundo del trabajo, de la que además participan sólo ciertos sectores sociales.

46. En el artículo 2, inciso cuarto del Código del Trabajo chileno: raza, color, sexo, edad, estado civil, sindicación, religión, opinión política, nacionalidad, ascendencia nacional $\mathrm{u}$ origen social.

47. DE LA PUEBLA, Ana: "Igualdad y discriminación en el ejercicio del poder disciplinario”. En: Relaciones Laborales, Sección Doctrina, Editorial La Ley, Tomo 2, 1994. Pág. 33.

Facultad de Derecho y Ciencias Sociales - Universidad de Valparaíso - Chile 
Estamos ante el mismo tribunal que se granjeó una condena internacional para el país, por parte de la Corte Interamericana, que fue muy precisa en señalar que no constató que fueran las leyes chilenas las discriminatorias. En el caso "Atala Riffo y niñas versus Chile" ${ }^{48}$, se condena al país por actuaciones de su Poder Judicial, puntualmente de sus Tribunales Superiores, en relación a, dicho sea de paso, una funcionaria suya ${ }^{49}$, la señora Karen Atala.

La jueza fue demandada por su ex marido por la obtención del cuidado personal de las hijas en común, fundado en que la señora Atala había comenzado una convivencia lésbica. La condena a Chile fue por la aplicación de la ley, al haberse creado una categoría por parte del Poder Judicial, cual es la orientación sexual, para privar de derechos a un persona, en este caso tan importantes como el cuidado de los hijos.

Es por ello que la Corte no ordenó, en el capítulo reparaciones, modificación a la ley. Pero sí capacitaciones permanentes ${ }^{50}$.

48. Caso Atala Riffo y Niñas versus Chile. Fondo, Reparaciones y Costas.

Sentencia del 24 de febrero de 2012. Serie C No 239. Disponible en: http:// www.corteidh.or.cr/casos.cfm? idCaso $=381$

49. La Corte Interamericana fue muy clara al señalar que no constató que fuera

la ley la chilena la que contuviera elementos discriminatorios, sino que en diversas actuaciones de los Tribunales se discriminó a la jueza, incluida una investigación disciplinaria que se origina en un hecho ajeno a su labor profesional, como es su relación de pareja. Aspecto sumamente atractivo considerando que el ejercicio de esta potestad tiene que ver con la relación laboral de la magistrada con sus superiores, en que media la jerarquía y la disciplina.

50. Sobre "i) derechos humanos, orientación y discriminación, ii) protección de los derechos de la comunidad de lesbianas, gays, bisexuales, transexuales e intersexuales (LGTBI), y iii) discriminación, superación de estereotipos de género en contra de la población LGTBI. Los cursos deben estar dirigidos a funcionarios públicos a nivel regional y nacional, y particularmente a funcionarios judiciales de todas las áreas y escalafones de la rama judicial", párr. 272. Continúa la Corte especificando que "Dentro de dichos programas y cursos de capacitación deberá hacerse una especial mención a la presente sentencia y a los diversos precedentes del corpus iuris de los derechos humanos relativos a la proscripción de la discriminación por orientación sexual y a la obligación de todas las autoridades y funcionarios de garantizar que todas las personas, sin discriminación por su orientación sexual, puedan gozar de todos y cada uno de los derechos establecidos en la Convención. Debe ponerse especial atención para este efecto, en normas y prácticas en el derecho interno que, sea intencionalmente o por sus resultados, pueden tener efectos discriminatorios en el ejercicio de derechos por personas pertenecientes a las minorías sexuales", párr. 271.

Revista de Ciencias Sociales - Número 64 (2014) - Universidad de Valparáíso - ISSN 0716-7725-Valparaíso, Chile 
El caso de las "Nanas de Chicureo" no es ni por asomo, un caso difícil: es un caso revelador. Y el impacto se produce probablemente, porque sólo muy de cuando en cuando, se muestran a la luz pública, concepciones de mundo y costumbres de grupos que tienen el poder suficiente de regularse al margen de la juridicidad.

\section{BIBLIOGRAFÍA}

ARENDT, Hannah: La condición humana, Paidós, (primera Edición en español), Barcelona, 2005.

ATRIA, Fernando: “¿Existen los derechos sociales?”. En: Discusiones Doxa, $\mathrm{N}^{\mathrm{o}} 4,2004$.

—_ Disponible en: http://bib.cervantesvirtual.com/FichaObra. html? Ref $=203013$

CAAMAÑO, Eduardo y UGARTE, José Luis: Negociación colectiva y libertad sindical: un enfoque crítico, Legalpublishing, Santiago de Chile, 2009.

COURTIS, Christian y ABRAMOVICH, Víctor: "Los anillos de la serpiente. Transformaciones del Derecho entre el trabajo y el consumo". En: Jueces para la Democracia, No 22, 1994.

DE LA PUEBLA, Ana: "Igualdad y discriminación en el ejercicio del poder disciplinario”. En: Relaciones Laborales, Sección Doctrina, Editorial La Ley, Tomo 2, 1994.

DE LA PUEBLA, Ana: "Igualdad y discriminación en el ejercicio del poder disciplinario”. En: Relaciones Laborales, Sección Doctrina,

Editorial La Ley, Tomo 2, 1994.

DWORKIN, Ronald: Taking Rights Seriously, Duckworth, Londres, Inglaterra, 1977.

EMBID, Antonio: "El Tribunal Constitucional y la protección de las libertades públicas en el ámbito privado”, REDA, N²5, 1980.

FRASER, Nancy: Iustitia Interrupta. Reflexiones críticas desde la posición "postsocialista”, Siglo del Hombre, Universidad de Los

Andes, Bogotá, 1997.

FERRAJOLI, Luigi: "El Derecho como sistema de garantía”. En: Revista Jueces para la democracia, No 16-17, 1992.

Facultad de Derecho y Ciencias Sociales - Universidad de Valparaíso - Chile 
GAMONAL, Sergio: Trabajo y Derecho, Legalpublishing (segunda edición), Santiago de Chile, 2012.

GAMONAL, Sergio y GUIDI, Caterina: Manual del contrato de trabajo, Legalpublishing, (primera edición), Santiago de Chile, 2010.

GAMONAL, Sergio y UGARTE, José Luis: "Acoso sexual y moral en el lugar de trabajo". En: XX Congreso Mundial de la Sociedad Chilena de Derecho del Trabajo y de la Seguridad Social, Santiago de Chile, 25-28 de septiembre de 2012.

GARBERÍ, José: Constitución y Derecho Procesal, Cuadernos Civitas, Thompson Reuters, Madrid, 2009.

HABERMAS, Jurgen: Facticidad y validez, Editorial Trotta, (sexta edición), Madrid, 2010.

OLÁSOLO, Héctor y GALAIN, Pablo: "La Influencia en la Corte Penal Internacional de la Jurisprudencia de la Corte Interamericana de Derechos Humanos en materia de acceso, participación y reparación de víctimas". En: Sistema Interamericano de protección de los Derechos Humanos y Derecho Penal Internacional, Konrad-Adenauer e. V, 2010. PALOMEQUE, Manuel Carlos: "Sindicato y proceso del trabajo". En: Derecho del trabajo y razón crítica. Libro dedicado al profesor Manuel Carlos Palomeque en su vigésimo quinto aniversario como catedrático, Salamanca, 2004.

PERSIANI, Mattia: "Il potere direttivo e l'organizzazione del lavoro". PERSIANI, Mattia y CARINCI, Franco, Trattato di Diritto del Lavoro, Cedam, Padova, 2012.

ROJAS, Gloria: El derecho del trabajador al ejercicio individual de las acciones derivadas del contrato de trabajo, Civitas, Madrid, 1994. "La libertad de expresión del trabajador", Trotta, Madrid, 1991.

UGARTE, José Luis: La colisión de derechos fundamentales en el contrato de trabajo y el principio de proporcionalidad, Tesis para optar al grado de doctor por la Universidad de Salamanca, 2012.

Disponible en: http://www.tesisenred.net/handle/10803/649/

browse ? value $=\mathrm{Ugarte}+\mathrm{Cataldo} \% 2 \mathrm{C}+\mathrm{Jos} \% \mathrm{C} 3 \% \mathrm{~A} 9+\mathrm{L} . \&$ type $=$ author

__ "El trabajador en su soledad- El modelo de relaciones laborales chileno y la promesa no cumplida”, 2010, (inédito).

Revista de Ciencias Sociales - Número 64 (2014) - Universidad de Valparáíso - ISSN 0716-7725-Valparaíso, Chile 
Disponible en:

CRUZ VILLALÓN, Jesús, "Constitución y proceso del trabajo". En: Valdés Dal-Ré, Fernando y Cruz Villalón, Jesús, Lecturas sobre la reforma del proceso laboral, Ministerio de Justicia, Centro de Publicaciones, Madrid, 1991.

VALDÉS DAL-RÉ, Fernando, "El proceso de protección de la libertad sindical y demás derechos fundamentales", en la obra colectiva Lecturas sobre la reforma del proceso laboral, Valdés Dal - Ré, Fernando y Cruz Villalón, Jesús, , Ministerio de Justicia, Centro de Publicaciones, Madrid, España, 1991.

VON MÜNCH, Ingo: "Drittwirkung de derechos fundamentales en Alemania". En: Cardoch, Pablo, Asociaciones, derechos fundamentales y autonomía privada, Civitas, Madrid, España, 1997.

Facultad de Derecho y Ciencias Sociales - Universidad de Valparaíso - Chile 